\title{
Eriocaulaceae na Reserva Natural da Vale, Linhares, Espírito Santo, Brasil
}

\author{
Eriocaulaceae from the Vale Natural Reserve Linhares, Espírito Santo, Brazil
}

Lucas Espindola Florêncio da Silva ${ }^{1,2}$ \& Marcelo Trovó ${ }^{1,2}$

\begin{abstract}
Resumo
Eriocaulaceae compreende aproximadamente 1400 espécies distribuídas em dez gêneros. Apesar da maior parte dos estudos taxonômicos na família se concentrarem na Cadeia do Espinhaço, as áreas de restinga possuem uma grande diversidade de espécies. Este trabalho fornece o tratamento florístico das Eriocaulaceae na Reserva Natural da Vale, no Espírito Santo. Foram encontradas nove espécies, distribuídas em seis gêneros: Actinocephalus, Comanthera, Leiothrix e Tonina com um representante cada e Syngonanthus e Paepalanthus com dois e três representantes, respectivamente. São fornecidas fotografias, descrições, chave de identificação, além de comentários sobre distribuição geográfica e variação morfológica das espécies.
\end{abstract}

Palavras-chave: flora, Paepalanthus, Syngonanthus, taxonomia, Vale do Rio Doce.

\begin{abstract}
Eriocaulaceae comprises ca. 1400 species arranged in ten genera. Most of the taxonomic efforts in the family are focused in the Espinhaço Range, its center of diversity. However, the sand dunes in Brazil have also a significant species richness. This manuscript presents the floristic treatment of the Eriocaulaceae from the Reserva Natural da Vale in Espírito Santo State. A total of nine species distributed in six genera were recorded. The genera Actinocephalus, Comanthera, Leiothrix, and Tonina are represented by one species each, Syngonanthus is represented by two species and Paepalanthus by three species. Photos, descriptions, an identification key, as well as comments on geographic distribution and morphological variation are provided.
\end{abstract}

Key words: flora, Paepalanthus, Syngonanthus, taxonomy, Vale do Rio Doce.

\section{Introdução}

Eriocaulaceae é caracterizada pelo hábito em roseta, de onde partem escapos portando inflorescências do tipo capítulo (Giulietti \& Hensold 1990; Giulietti et al. 1995; Giulietti et al. 2000; Stützel 1998). A família possui distribuição Pantropical com dez gêneros e cerca de 1400 espécies, das quais 700 ocorrem no Neotrópico (Giulietti et al. 2000; Giulietti et al. 2012). O principal centro de diversidade de Eriocaulaceae no Brasil é a Cadeia do Espinhaço (Giulietti \& Hensold 1990; Stützel 1998), onde estão concentrados a maior parte dos esforços florísticos para a família (Giulietti \& Hensold 1987; Giulietti \& Hensold 1990; Giulietti et al. 1987; Giulietti \& Parra 1995; Giulietti et al. 2003; Harley \& Simmons 1986; Hensold 1998; Miranda
\& Giulietti 2001; Parra 1998; Sano 1998; Sano et al. 2010). Entretanto, outras áreas no Brasil Central, ou mesmo as restingas, também possuem uma riqueza de espécies considerável, mas são insuficientemente estudadas.

A Reserva Natural da Vale possui cerca de 22.000 hectares e localiza-se entre os municípios de Linhares e Jaguaré ao norte do estado do Espírito Santo $\left(19^{\circ} 6^{\prime}-19^{\circ} 18^{\prime} \mathrm{S} ; 39^{\circ} 45^{\prime}-40^{\circ} 19^{\prime} \mathrm{W}\right)$. Cerca de $10 \%$ da área da reserva é ocupada pelo campo nativo, que possui uma composição florísticas semelhante à das restingas do sudeste do Brasil (Peixoto 1982). A floresta de tabuleiro, ou floresta ombrófila densa de terras baixas destaca-se por ser o principal tipo de vegetação presente na reserva (Veloso et al. 1991; Rizzini 1997). Estão presentes também a floresta de várzea e a

\footnotetext{
${ }^{1}$ Universidade Federal do Rio de Janeiro, Depto. Botânica, Inst. Biologia, CCS, Bloco A1, Cidade Universitária, 21941-590, Rio de Janeiro, RJ, Brasil.

${ }^{2}$ Autores para correspondência: lucasespindola.ufrj@gmail.com, martrovo@gmail.com
} 
floresta de muçununga. Estes tipos de vegetação estão associados às diferentes características geomorfológicas do substrato e abrigam uma grande diversidade de espécies vegetais (Garay et al. 2003).

A falta de conhecimento sobre as Eriocaulaceae em diversas áreas, revela a importância no entendimento e aprofundamento da diversidade taxonômica e morfológica da família. Trabalhos envolvendo tratamento florístico são desejáveis, informando a distribuição geográfica e morfologia das espécies, embasando inclusive estudos de conservação na família. Este trabalho tem por objetivo o tratamento florístico das espécies de Eriocaulaceae ocorrentes na Reserva Natural Vale, contribuindo para o aprofundamento do conhecimento da família nas restingas e a conservação e monitoramento da família na Unidade de Conservação.

\section{Materiais e Métodos}

O tratamento florístico tem como base os materiais consultados em visitas aos herbários CVRD, GUA, MBML, R, RB, RFA, SPF e VIES. Os dados obtidos nestes herbários foram somados aos materiais coletados em duas expedições na Reserva Natural da Vale. Os espécimes coletados foram depositados no herbário CVRD, com duplicatas enviadas para outras instituições. A terminologia proposta por Radford (1974) foi utilizada para análises morfológicas de estruturas vegetativas, enquanto a terminologia proposta por Weberling (1989) foi utilizada para descrição de estruturas reprodutivas. É apresentada uma chave de identificação para as espécies, além de descrições, comentários e fotos.

\section{Resultados e Discussão}

Neste trabalho foram encontradas 9 espécies de Eriocaulaceae distribuídas em seis gêneros. O gênero Paepalanthus Mart. possui 3 espécies na Reserva: Paepalanthus bifidus (Schrad.) Kunth,
Paepalanthus klotzschianus Koern. e Paepalanthus tortilis (Bong.) Mart. O gênero Syngonanthus Ruhland possui dois representantes: Syngonanthus gracilis (Bong.) Ruhland e Syngonanthus restingensis Hensold \& A.L.R. Oliveira. O restante dos gêneros possui apenas um representante cada, sendo elas: Actinocephalus ramosus (Wikstr.) Sano, Comanthera nivea (Bong.) L.R. Parra \& Giul., Leiothrix hirsuta (Wikstr.) Ruhland e Tonina fluviatilis Aubl. Entretanto, A. ramosus é a espécie que possui maior número de indivíduos coletados na Reserva Natural da Vale. É a espécie mais frequente, encontrada em quase todas as formações abertas da Reserva Natural da Vale e seus arredores. A espécie T. fluviatilis foi encontrada às margens de áreas alagadas, enquanto as demais espécies foram encontradas em locais majoritariamente secos com vegetação graminóide. Syngonanthus restingensis, listada em risco de extinção, tinha sua distribuição atribuída somente as restingas da Bahia e Rio de Janeiro (Hensold et al. 2012). No entanto, os dados obtidos neste estudo mostram que a espécie também está presente no Espírito Santo.

Outros tratamentos florísticos nos arredores do Espírito Santo mostram que a distribuição de Eriocaulaceae estende-se das regiões montanhosas às restingas. No Parque Nacional do Caparaó foram encontradas somente quatro espécies, das quais duas são endêmicas da região. Contudo, sendo o Caparaó uma região de altitude, as espécies encontradas não coincidem com a Reserva Natural da Vale (Trovó et al. 2007). Nas restingas do estado do Rio de Janeiro estão presentes doze espécies distribuídas em seis gêneros (Silva \& Trovó 2014). O presente trabalho revelou que das doze que ocorrem no Rio de Janeiro, nove espécies têm ocorrência na Reserva Natural da Vale. Assim, embora a Reserva Natural da Vale possua uma área reduzida em comparação com as restingas fluminenses, o número de espécies é praticamente o mesmo e a diversidade de gêneros se mantém (Silva \& Trovó 2014).

\section{Chave de identificação das espécies de Eriocaulaceae}

1. Escapos unidos em arranjos umbeliformes no ápice de ramos laterais formando inflorescências numerosas 1. A. ramosus

1'. Escapos partindo da axila das folhas, geralmente solitários, quando em arranjo umbeliforme então formando inflorescência única apical.

2. Pétalas das flores pistiladas reduzidas a lobos com longos tricomas. Espatas abertas 
2'. Pétalas das flores pistiladas desenvolvidas. Espatas fechadas .......................................................... 3

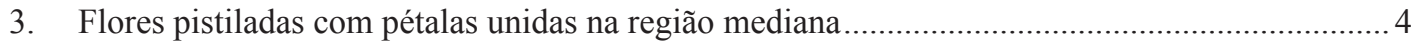

4. Brácteas florais ausentes, brácteas involucrais vistosas, ultrapassando o diâmetro do capítulo

2. C. nivea

4'. Brácteas florais presentes, brácteas involucrais não vistosas, não ultrapassando o diâmetro do capítulo.

5. Folhas lineares, com 0,5-1,7 cm compr., 0,1 cm larg. Espatas com 1,2-2,8 cm compr.

7. S. gracilis

5'. Folhas lanceoladas, com 6,5-21,4 cm compr., 0,5-1 cm larg. Espatas com 3,9-6,1 cm compr.

8. S. restingensis

3'. Flores pistiladas com pétalas totalmente livres

6. Ramos estigmáticos e ramos nectaríferos liberando-se na coluna do gineceu em alturas diferentes, anteras basifixas.

3. L. hirsuta

6'. Ramos estigmáticos e nectaríferos liberando-se na coluna do gineceu na mesma altura, anteras dorsifixas .....

7. Folhas com margem ciliada, brácteas involucrais esverdeadas, lanceolado-lineares .....

4. P. bifidus

7'. Folhas com margem glabra, brácteas involucrais castanhas ou negras, elípticas ou obovais .....

8. Folhas dispostas em roseta, lanceoladas, brácteas involucrais castanhas, com ca. 3 mm de compr., brácteas florais castanhas

5. P. klotzschianus

8'. Folhas dispostas ao longo do caule, lineares, brácteas involucrais negras, com ca. $2 \mathrm{~mm}$ de compr., brácteas florais negras

6. P. tortilis

\section{Actinocephalus ramosus (Wikstr.) Sano, Taxon} 53: 104. 2004.

Fig. 1a,b

Plantas de 30,1-83,2 cm alt. Folhas dispostas em roseta, $6,6-15 \times 0,5-1 \mathrm{~cm}$, lanceoladas, superfícies pilosas à glabrescentes, margens ciliadas à glabrescente, ápice agudo. Espatas 0,4-1,5 cm compr., fechadas, pilosa na face abaxial, ápice agudo. Escapos unidos em arranjos umbeliformes no ápice de ramos laterais, formando florescências numerosas, 1,3-7,8 cm compr., piloso. Capítulos alvos, ca. 4 mm diâm., obcônicos. Brácteas involucrais castanhas, ca. $2 \mathrm{~mm}$ compr., não ultrapassando o diâmetro do capítulo, obovais, pouco pilosas à glabrescentes, margens ciliadas, ápice agudo à raramente obtuso. Brácteas florais castanhas, ca. $2 \mathrm{~mm}$ compr., obovais-lineares, superfícies pouco pilosas à glabrescentes, margens ciliadas, ápice agudo. Flor estaminada ca. $2 \mathrm{~mm}$ compr., pedicelo $0,5-1 \mathrm{~mm}$ compr., com longos tricomas; sépalas castanhas, obovais, superfícies glabras, margens ciliadas, ápice acuminado-agudo; pétalas castanhas, anteras dorsifixas, pistilódio papiloso. Flor pistiladas ca. $2 \mathrm{~mm}$ compr., séssil; sépalas castanhas, obovais, superfícies pilosas à glabrescentes, margens ciliadas, ápice agudo; pétalas totalmente livres, castanhas-hialinas, lanceoladas, superfícies pilosas à glabrescentes, margens ciliadas, ápice agudo; ramos estigmáticos simples, maiores que os ramos nectaríferos. Ramos estigmáticos e nectaríferos liberando-se na coluna do gineceu na mesma altura.

Comentários: Pode ser diferenciada das demais espécies da área por possuir hábito robusto portando inflorescências umbeliformes no ápice de ramos laterais que crescem sobre um eixo central de inflorescência (Sano 2004). No Brasil está distribuída na Bahia, Espírito Santo, Minas Gerais e Rio de Janeiro (Ruhland 1903; BFG 2015). Nos arredores e dentro da reserva ocorre em abundância, sendo a espécie mais comum da família na região. Apresenta flores e frutos praticamente o ano todo, principalmente nos meses mais úmidos.

Material examinado selecionado: Linhares, 9.V.2009, P.J.M. Maas et al. 9869 (CVRD, RFA); 28.XI.2009, A.M. Assis 2241 (MBML); 18.V.2010, V.B.R. Ferreira 58 (VIES); 9.VI.2010, V.B.R. Ferreira 88 (VIES); 18.VI.2010, V.B.R. Ferreira 109 (VIES); 26.X.2010, T.B. Flores 942 (CVRD); 18.IV.2011, J.C. Lopes et al. 256 (RB); 5.XII.2012, J.A. Lombardi et al. 9654 (CVRD, RFA); 6.XI.2014, L.E.F. Silva 31 (CVRD, RFA); 7.XI.2014, L.E.F. Silva 37 (CVRD, RFA).

2. Comanthera nivea (Bong.) L.R. Parra \& Giul., Taxon 59: 1141-1142. $2010 . \quad$ Fig. 1c

Plantas de 13,4-30,9 cm alt. Folhas dispostas em roseta, 0,9-4,2 ×0,1 cm, lineares, superfícies pilosas em ambas as faces à glabrescentes, margens 


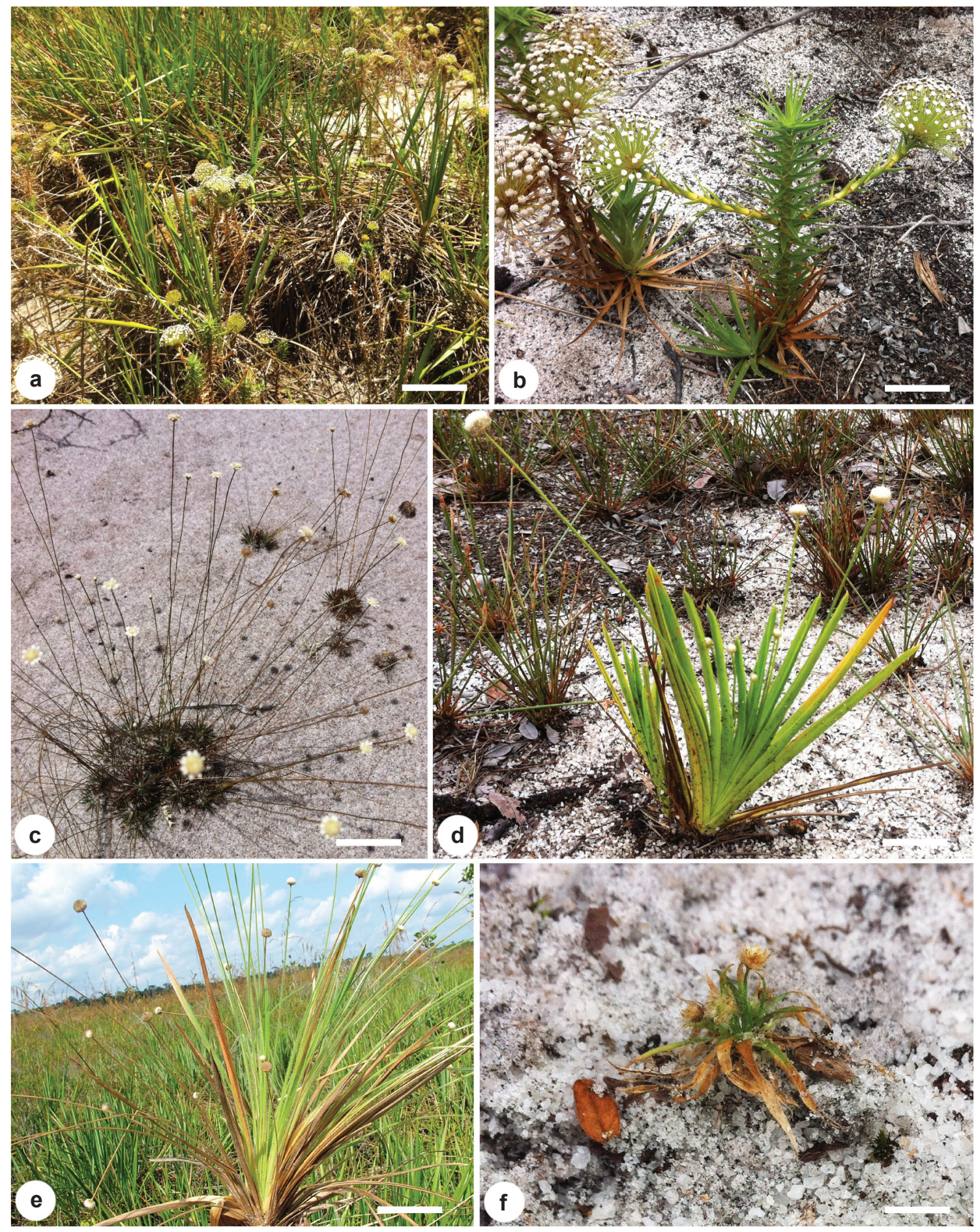

Figura 1 - Hábito e habitat das espécies de Eriocaulaceae ocorrentes na Reserva Natural da Vale. - a. Actinocephalus ramosus; b. Actinocephalus ramosus; c. Comanthera nivea; d. Leiothrix hirsuta; e. Leiothrix hirsuta; f. Paepalanthus bifidus. (fotos: a-f, Marcelo Trovó). Barras de escala: a. 20 cm; b. 10 cm; c. 2 cm; d. 2 cm; e. 3 cm; f. 1 cm.

Figure 1 - Habit and habitat of the Eriocaulaceae species from the Reserva Natural da Vale. - a. Actinocephalus ramosus; b. Actinocephalus ramosus; c. Comanthera nivea; d. Leiothrix hirsuta; e. Leiothrix hirsuta; f. Paepalanthus bifidus. (photos: a-f, Marcelo Trovó). Scale bars: a. $20 \mathrm{~cm}$; b. 10 ; c. $2 \mathrm{~cm}$; d. $2 \mathrm{~cm}$; e. $3 \mathrm{~cm}$; f. $1 \mathrm{~cm}$. 
ciliadas, ápice obtuso-arredondado. Espatas 2,3-4 cm compr. fechadas, pubescente na face abaxial à glabrescentes, ápice obtuso. Escapos partindo da axila das folhas, geralmente solitários, quando em arranjo umbeliforme então formando florescência única apical, 7,9-28,4 cm compr., pubescente entre as costelas à glabrescentes. Capítulos alvos, ca. $3 \mathrm{~mm}$ diâm., hemisféricos. Brácteas involucrais brancas, vistosas, ca. $3 \mathrm{~mm}$ compr. Ultrapassando o diâmetro do capítulo, obovais, superfícies glabras, margens glabras, ápice arredondado. Brácteas florais ausentes. Flor estaminada 1,5-2 mm compr., pedicelo ca. 0,5 mm compr., com longos tricomas; sépalas hialinas, elípticas, superfícies glabras, margens glabras, ápice arredondado; pétalas hialinas, anteras dorsifixas, pistilódio papiloso. Flor pistilada 2-2,5 mm compr., pedicelo com longos tricomas; sépalas hialinas, elípticas, superfícies glabras, margens glabras, ápice arredondado; pétalas desenvolvidas, unidas na região mediana, hialinas, lineares, superfícies glabras, margens glabras, ápice arredondado; ramos estigmáticos simples, maiores que os ramos nectaríferos. Ramos estigmáticos e nectaríferos liberando-se na coluna do gineceu na mesma altura.

Comentários: Pode ser distinta das demais espécies pelas vistosas brácteas involucrais alvas que superam o diâmetro do capítulo (Parra et al. 2010). Sua distribuição está relacionada ao Espírito Santo, Minas Gerais, Rio de Janeiro e São Paulo (Ruhland 1903; Sano \& Giulietti 2012; BFG 2015). $\mathrm{Na}$ reserva, ocorre em regiões arenosas secas, formando muitas vezes populações agregadas. Apresenta flores e frutos entre outubro e fevereiro. Material examinado selecionado: Linhares, 3.II.1972, D. Sucre 8399 (RB); 23.III.1986, M. Sobral 4692 (CVRD); 28.XI.2009, A.M. Assis 2231 (MBML); 7.XI.2014, L.E.F. Silva 35 (CVRD, RFA).

3. Leiothrix hirsuta (Wikstr.) Ruhland, Pflanzenr. (Engler) 4, Fam. 30: 229. $1903 . \quad$ Fig. 1d,e

Plantas de 22,5-64,1 cm alt. Folhas dispostas em roseta, 4-39,7 × 0,3-1,1 cm, lanceoladas, superfícies hirsutas em ambas as faces, margens ciliadas, ápice obtuso. Espatas 3-9,1 cm compr., fechadas, hirsutas, ápice agudo. Escapos partindo da axila das folhas, geralmente solitários, quando em arranjo umbeliforme então formando florescência única apical, 6,5-61,9 $\mathrm{cm}$ compr., hirsutos. Capítulos creme, ca. $5 \mathrm{~mm}$ diâm., hemisféricos. Brácteas involucrais creme, 2,5-4 mm compr., não ultrapassando o diâmetro do capítulo, elípticasobovais, superfícies glabras, margens glabras, ápice agudo. Brácteas florais hialinas, ca. $4 \mathrm{~mm}$ compr., obovais, superfícies glabras, margens glabras, ápice agudo. Flor estaminada ca. $3 \mathrm{~mm}$ compr., pedicelo ca. 0,5 mm compr., com longos tricomas; sépalas hialinas, elípticas, superfícies glabras, margens glabras, ápice agudo; pétalas hialinas, anteras basifixas, pistilódio papiloso. Flor pistilada ca. $4 \mathrm{~mm}$ compr., séssil; sépalas hialinas, elípticas, superfícies glabras, margens glabras, ápice agudo; pétalas desenvolvidas, totalmente livres, hialinas, elípticas, superfícies glabras, margens glabras, ápice agudo; ramos estigmáticos simples, maiores que os ramos nectaríferos. Ramos estigmáticos e nectaríferos liberando-se na coluna do gineceu em alturas diferentes.

Comentários: São plantas robustas com folhas geralmente hirsutas e dísticas, características incomuns ao gênero e únicas dentre as espécies que ocorrem na reserva. No Brasil há registro na Bahia, Espírito Santo, Minas Gerais e Rio de Janeiro (Ruhland 1903; BFG 2015). Na reserva, ocorre em locais secos ou úmidos, associados à borda de brejos. Apresenta flores e frutos praticamente o ano todo, com a floração iniciando nos meses mais úmidos.

Material examinado selecionado: Linhares, 6.IV.2006, J.G. Rando et al. 164 (CVRD, RB); 30.V.2006, D.A. Folli 5289 (CVRD, RFA); 6.VII.2006, M.L.O. Trovó 253 (CVRD, RFA); 7.II.2007, J.R. Stehmann et al. 4660 (CVRD, RFA); 18.VI.2010, V.B.R. Ferreira 110 (CVRD, VIES); 25.VI.2010, V.B.R. Ferreira 98 (CVRD, VIES); 13.X.2010, V.B.R. Ferreira 136 (VIES); 28.VIII.2012, T.B. Flores \& G.O. Romão 1240 (CVRD); 6.XI.2014, L.E.F. Silva 27 (CVRD, RFA); 7.XI.2014, L.E.F. Silva 38 (CVRD, RFA).

4. Paepalanthus bifidus (Schrad.) Kunth, Enum. Pl. 3: 512. $1841 . \quad$ Fig. 1f

Plantas de 1,5-15,2 cm alt. Folhas dispostas ao longo do caule, $0,3-3,6 \times 0,1 \mathrm{~cm}$, lineares, superfícies lanuginosas em ambas as faces, margens ciliadas, ápice obtuso. Espatas 1-2,3 cm compr., fechadas, lanuginosa, ápice obtuso. Escapos partindo da axila das folhas, no ápice do caule, geralmente solitários, quando em arranjo umbeliforme então formando florescência única apical, 0,2-6 cm compr., piloso. Capítulos creme, ca. $3 \mathrm{~mm}$ diâm., hemisféricos. Brácteas involucrais esverdeadas, ca. $3 \mathrm{~mm}$ compr., não ultrapassando o diâmetro do capítulo, lanceoladas-lineares, superfícies glabras, margens glabras, ápice obtuso. Brácteas florais castanhas, ca. $2 \mathrm{~mm}$ compr., ovada, superfícies pilosas à glabrescentes, margens ciliadas, ápice agudo. Flor estaminada ca. $2 \mathrm{~mm}$ compr., pedicelo ca. $0,5 \mathrm{~mm}$ compr., com longos 
tricomas; sépalas hialinas, elípticas, superfícies pilosas à glabrescentes, margens ciliadas, ápice agudo; pétalas hialinas, anteras dorsifixas, pistilódio papiloso. Flor pistilada ca. $2 \mathrm{~mm}$ compr., séssil; sépalas hialinas, obovais, superfícies glabras, margens glabras, ápice acuminado; pétalas desenvolvidas, totalmente livres, hialinas, elípticas, superfícies glabras, margens ciliadas, ápice agudo; ramos estigmáticos simples, maiores que os ramos nectaríferos. Ramos estigmáticos e nectaríferos liberando-se na coluna do gineceu na mesma altura.

Comentários: Possuindo geralmente poucos centímetros, é uma espécie de hábito muito delicado. Pode ser distinguida das demais espécies pelas folhas dispostas ao longo de um caule evidente e por suas brácteas involucrais lineares esverdeadas. Ocorre no Brasil, Colômbia, Guiana e Suriname. No Brasil, tem ocorrência registrada para os estados Alagoas, Amazonas, Bahia, Ceará, Espírito Santo, Maranhão, Minas Gerais, Pará, Paraíba, Pernambuco, Piauí, Rio de Janeiro, Rio Grande do Norte e Sergipe (Ruhland 1903; BFG 2015). Na reserva, ocorre em solos arenosos secos na beira de estradas. Apresenta flores e frutos o ano todo, com maior frequência nos meses mais úmidos. Material examinado selecionado: Linhares, 11.XI.1992, D.A. Folli 1731 (CVRD); 20.II.1997, D.A. Folli 2937 (CVRD, RFA); 7.VIII.2000, O.J. Pereira et al. 6323 (VIES); 5.IV.2006, G.O. Romão 1233 (CVRD); 6.VII.2006, M.L.O. Trovó 256 (CVRD, RFA); 8.II.2007, J.R. Stehmann 4768 (CVRD); 17.IV.2011, R. Morokawa 402 (RB); 1.IX.2011, V.B.R. Ferreira 154 (CVRD, VIES); 6.XI.2014, L.E.F. Silva 28 (CVRD, RFA); 7.XI.2014, L.E.F. Silva 39 (CVRD, RFA).

5. Paepalanthus klotzschianus Körn. in Mart., Fl. bras. 3(1): 389. 1864.

Fig. 2a,b

Plantas de 20,4-44,1 cm alt. Folhas dispostas em roseta, 3,9-11 × 0,3-0,8 cm, lanceoladas, superfícies seríceas à glabrescentes, margens glabras, ápice agudo. Espatas 5,9-10 cm compr., fechadas, densamente pubescente, ápice agudo. Escapos partindo da axila das folhas, geralmente solitários, quando em arranjo umbeliforme então formando florescência única apical, 10,6-35,6 cm compr., glabras. Capítulos castanhos, ca. 10 $\mathrm{mm}$ diâm., hemisféricos. Brácteas involucrais castanhas, ca. $3 \mathrm{~mm}$ compr., não ultrapassando o diâmetro do capítulo, elíptica, superfícies pouco pilosas à glabrescentes, margens glabras, ápice agudo. Brácteas florais castanhas, ca. 3 $\mathrm{mm}$ compr., obovais, superfícies pouco pilosas à glabrescentes, margens glabras, ápice agudo. Flor estaminada ca. $3 \mathrm{~mm}$ compr., pedicelo ca.
0,5 mm compr., com longos tricomas; sépalas hialinas, obovais, superfícies glabras, margens ciliadas à glabrescentes, ápice acuminado; pétalas hialinas, anteras dorsifixas, pistilódio papiloso. Flor pistilada ca. $3 \mathrm{~mm}$ compr., séssil; sépalas castanhas, elípticas obovais, superfícies glabras, margens ciliadas à glabrescentes, ápice acuminado; pétalas desenvolvidas, totalmente livres, castanhas, obovais, superfícies glabras, margens ciliadas, ápice acuminado; ramos estigmáticos bífidos, maiores do que os ramos nectaríferos. Ramos estigmáticos e nectaríferos liberando-se na coluna do gineceu na mesma altura.

Comentários: Facilmente distinta das demais espécies de Paepalanthus que ocorrem na reserva por ser a única com hábito em roseta, possuir longos escapos e folhas densamente pilosas. No Brasil é tem registros para os estados da Bahia, Espírito Santo e Rio de Janeiro (BFG 2015). $\mathrm{Na}$ reserva, ocorre em solos arenosos secos e predominantemente sombreados. Apresenta flores e frutos durante o ano todo, mais frequentemente após o início do período chuvoso.

Material examinado selecionado: Linhares, 1.II.1972, D. Sucre 8390 (RB); 15.IX.1985, D.A. Folli 725 (CVRD, RFA); 17.IX.1987, G. Martinelli et al. 12232 (RB); 4.VIII.1999, D.A. Folli 3465 (CVRD, RFA); 7.VIII.2000, O.J. Pereira et al. 6313 (VIES); 6.VII.2006, M.L.O. Trovó 257 (CVRD, RFA); 18.V.2010, V.B.R. Ferreira 57 (VIES); 9.VI.2010, V.B.R. Ferreira 90 (VIES); 6.XI.2014, L.E.F. Silva 32 (CVRD, RFA); 7.XI.2014, L.E.F. Silva 36 (CVRD, RFA).

6. Paepalanthus tortilis (Bong.) Mart. in Mart., Fl. bras. 3(1): 354. 1864.

Fig. 2c

Plantas de 4-29,8 cm alt. Folhas dispostas ao longo do caule, $0,6-2,9 \times 0,1-0,2 \mathrm{~cm}$, lineares, superfícies glabras ou raramente pilosas em ambas as faces, margens glabras, ápice obtuso. Espatas 1,1-3,2 cm compr., fechadas, hirsutas-pilosas, ápice agudo. Escapos partindo da axila das folhas no ápice do caule, geralmente solitários, quando em arranjo umbeliforme então formando florescência única apical, 2,7-21 cm compr., glabros ou pilosos entre as costelas. Capítulos negros, ca. 3 mm diâm., cônico. Brácteas involucrais negras, ca. $2 \mathrm{~mm}$ compr., não ultrapassando o diâmetro do capítulo, obovais, superfícies glabras, margens ciliadas à glabrescentes, ápice acuminado. Brácteas florais negras, ca. $1 \mathrm{~mm}$ compr., obovais, superfícies pilosas à glabrescentes, margens ciliadas à glabrescentes, ápice acuminado. Flor estaminada ca. $1 \mathrm{~mm}$ compr., pedicelo ca. $0,5 \mathrm{~mm}$ compr., com pequenos tricomas; sépalas esverdeadas, obovais, 

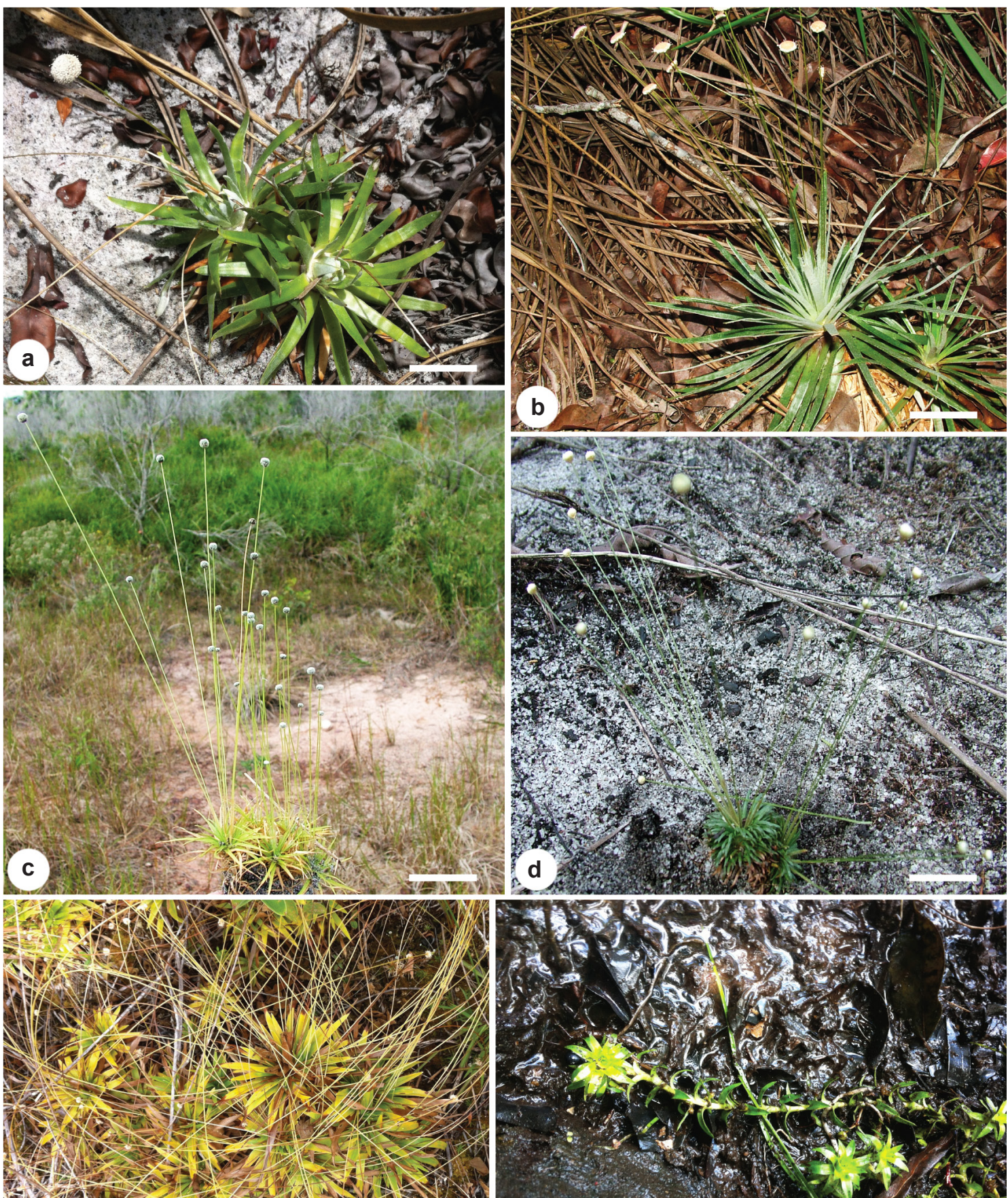

4)

4.

e
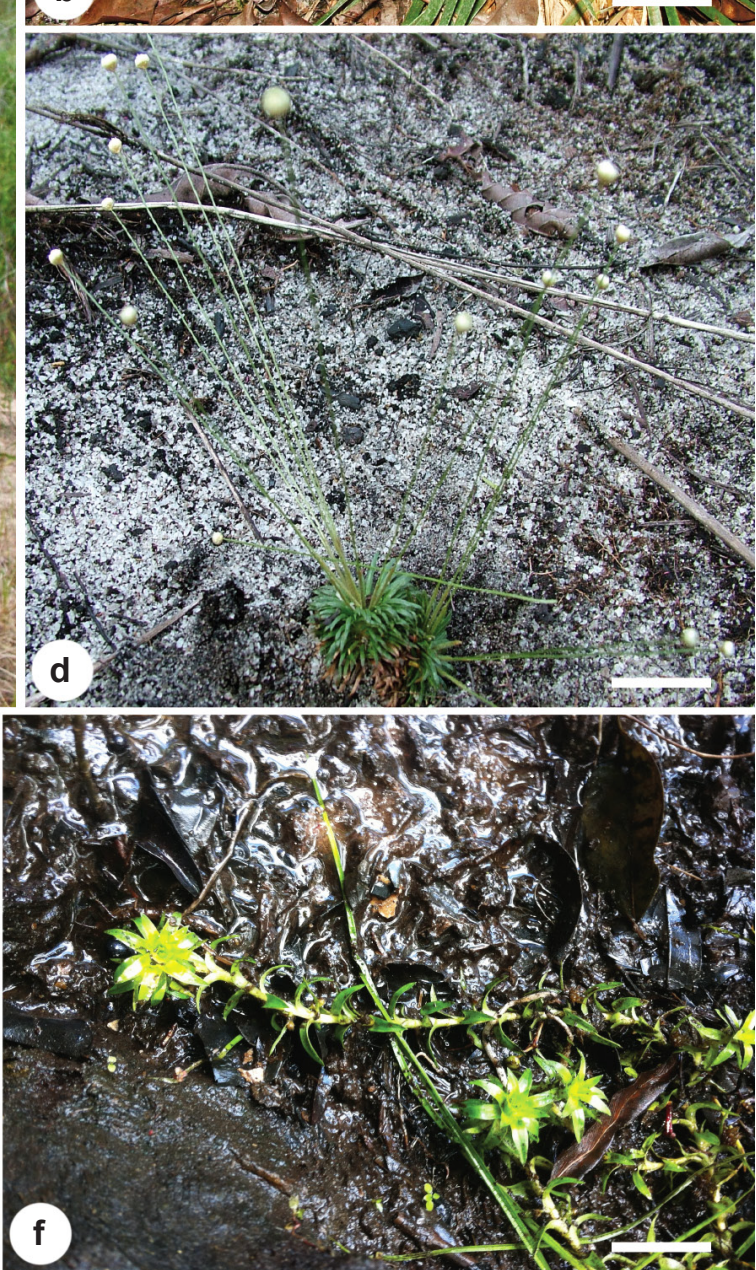

Figura 2 - Hábito e habitat das espécies de Eriocaulaceae ocorrentes na Reserva Natural do Vale. - a. Paepalanthus klotzschianus; b. Paepalanthus klotzschianus; c. Paepalanthus tortilis; d. Syngonanthus gracilis; e. Syngonanthus restingensis; f. Tonina fluviatilis. (fotos: a-f, Marcelo Trovó). Barras de escala: a. $5 \mathrm{~cm}$; b. 8 cm; c. $6 \mathrm{~cm}$; d. 2,5 cm; e. 15 cm; f. 4 cm.

Figure 2 - Habit and habitat of the Eriocaulaceae species from the Reserva Natural do Vale. - a. Paepalanthus klotzschianus; b. Paepalanthus klotzschianus; c. Paepalanthus tortilis; d. Syngonanthus gracilis; e. Syngonanthus restingensis; f. Tonina fluviatilis. (photos: a-f, Marcelo Trovó). Scale bars: a. $5 \mathrm{~cm}$; b. 8 cm; c. $6 \mathrm{~cm}$; d. 2,5 cm; e. 15 cm; f. 4 cm. 
superfícies pilosas à glabrescentes, margens ciliadas à glabrescentes, ápice acuminado; pétalas hialinas, anteras dorsifixas, pistilódio papiloso. Flor pistilada ca. $1 \mathrm{~mm}$ compr., séssil; sépalas negras, obovais, superfícies pilosas à glabrescentes, margens ciliadas à glabrescentes, ápice acuminado; pétalas desenvolvidas, totalmente livres, hialinas, obovais, superfícies pilosas, margens ciliadas, ápice agudo; ramos estigmáticos simples, maiores que os ramos nectaríferos. Ramos estigmáticos e nectaríferos liberando-se na coluna do gineceu na mesma altura.

Comentários: Espécies de caule ligeiramente alongado e hábito grácil. Distinta das demais espécies presente na reserva por possuir coloração escura nos capítulos, brácteas involucrais e brácteas florais. Possui distribuição geográfica bastante ampla. Na América do Sul ocorre no Brasil, Colômbia e Venezuela. No Brasil tem registros para os estados de Alagoas, Amazonas, Bahia, Ceará, Espírito Santo, Minas Gerais, Pernambuco, Rio de Janeiro, Roraima, Sergipe (Ruhland 1903; BFG 2015). Na reserva, ocorre em regiões de solos arenosos secos ou úmidos e em borda de lagoas. Apresenta flores e frutos praticamente o ano todo. Material examinado selecionado: Linhares, 4.III.1993, D.A. Folli 1826 (CVRD, RFA); 24.I.2000, C.N. Fraga 584 (MBML); 24.III.2004, D.A. Folli 4794 (CVRD, RFA); 23.VI.2005, B.R. Silva \& M. Nadruz 1393 (RB); 8.IV.2006, G.Q. Freire 103 (CVRD); 7.II.2007, J.R. Stehmann et al. 4667 (CVRD, RFA); 8.II.2007, J.R. Stehmann et al. 4769 (CVRD, RFA); 10.V.2007, D.A. Folli 5580 (CVRD, RFA); 6.XI.2014, L.E.F. Silva 30 (CVRD, RFA); 7.XI.2014, L.E.F. Silva 40 (CVRD, RFA).

7. Syngonanthus gracilis (Bong.) Ruhland, Pflanzenr. (Engler) 4, Fam. 30: 249. 1903.

Fig. 2d

Plantas de 7,4-29,7 cm alt. Folhas dispostas em roseta, $0,5-1,7 \times 0,1 \mathrm{~cm}$, lineares, superfícies seríceas em ambas as faces, margens ciliadas à glabrescentes, ápice obtuso. Espatas 1,2-2,8 $\mathrm{cm}$ compr., fechadas, pilosas na face abaxial, ápice obtuso. Escapos partindo da axila das folhas, geralmente solitários, quando em arranjo umbeliforme então formando florescência única apical, 4,7-26,5 cm compr., pilosos. Capítulos creme, ca. $4 \mathrm{~mm}$ diâm., hemisféricos. Brácteas involucrais hialinas, ca. $2 \mathrm{~mm}$ compr., inconspícuas, não ultrapassando o diâmetro do capítulo, elípticas, superfícies glabras, margens ciliadas à glabrescentes, ápice obtuso. Brácteas florais hialinas, ca. $3 \mathrm{~mm}$ compr., elípticas, superfícies glabras, margens glabras, ápice agudo. Flor estaminada ca. $2 \mathrm{~mm}$ compr., pedicelo ca. 1 mm compr., com longos tricomas; sépalas hialinas, elípticas, superfícies glabras, margens glabras, ápice agudo; pétalas hialinas, anteras dorsifixas. Flor pistilada ca. $3 \mathrm{~mm}$ compr., séssil; sépalas hialinas, elípticas, superfícies glabras, margens glabras, ápice agudo; pétalas desenvolvidas, unidas na região mediana, hialinas, elípticas, superfícies pilosas à glabrescentes, margens ciliadas, ápice agudo; ramos estigmáticos simples, maiores que os ramos nectaríferos. Ramos estigmáticos e nectaríferos liberando-se na coluna do gineceu na mesma altura.

Comentários: Espécie de hábito grácil e capítulos alvos. Distinta das demais espécies que ocorrem na reserva por seus capítulos glabros e pequenas folhas em roseta. Seus indivíduos são em geral solitários e crescem em solo arenoso em pleno sol. Distribui-se na Bolívia, Brasil, Uruguai e Venezuela. No Brasil tem registros para os estados do Amazonas, Bahia, Ceará, Distrito Federal, Espírito Santo, Goiás, Maranhão, Mato Grosso do Sul, Minas Gerais, Pará, Paraíba, Paraná, Rio de Janeiro, Rondônia, Roraima, Santa Catarina e São Paulo (Ruhland 1903; Sano \& Giulietti 2012; BFG 2015). Na reserva, ocorre em solos arenosos e secos, ocasionalmente em borda de estradas e em regiões temporariamente alagadas. Apresenta flores e frutos geralmente após o período chuvoso. Material examinado selecionado: Linhares, 24.III.2004, D.A. Folli 4793 (CVRD); 6.IV.2006, J.G. Rando et al. 168 (RB); 6.VII.2006, M.L.O. Trovó 254 (CVRD, RFA); 7.VII.2006, G.S. Siqueira 224 (CVRD, RFA); 7.II.2007, J.R. Stehmann 4658 (CVRD); 30.XI.2009, J.C.A. de Lima 04 (RB); 1.IX.2011, V.B.R. Ferreira 155 (CVRD); 18.II.2014, L. Biral 957 (CVRD); 6.XI.2014, L.E.F. Silva 26 (CVRD, RFA); 7.XI.2014, L.E. F. Silva 41 (CVRD, RFA).

8. Syngonanthus restingensis Hensold \& A.L.R. Oliveira, Phytotaxa 40: 2. $2012 . \quad$ Fig. 2e

Plantas de 22,9-51,7 cm alt. Folhas dispostas em roseta, $6,5-21,4 \times 0,5-1 \mathrm{~cm}$, lanceoladas, superfícies pilosas em ambas as faces quando jovem à glabrescente, margens ciliadas à glabrescentes, ápice obtuso. Espatas 3,9-6,1 cm compr., fechadas, pilosas à glabrescentes, ápice obtuso. Escapos partindo da axila das folhas, geralmente solitários, quando em arranjo umbeliforme então formando florescência única apical, 6,3-43,6 cm compr., pilosos. Capítulos creme, ca. 6-7,5 mm diâm., hemisféricos. Brácteas involucrais creme, ca. 3 mm compr., inconspícuas, não ultrapassando o diâmetro do capítulo, ovais, superfícies glabras, margens ciliadas à glabrescentes, ápice agudo. 
Brácteas florais hialinas, ca. 2,5 mm compr., lineares, superfícies glabras, margens ciliadas à glabrescentes, ápice agudo. Flor estaminada ca. $2 \mathrm{~mm}$ compr., pedicelo ca. 0,5 mm compr., com longos tricomas; sépalas hialinas, obovais, superfícies glabras, margens glabras, ápice obtuso; pétalas castanhas, anteras dorsifixas. Flor pistilada ca. 2,5 mm compr., pedicelo ca. 0,5 mm, com longos tricomas; sépalas hialinas, elípticas, superfícies glabras, margens glabras, ápice acuminado; pétalas desenvolvidas, unidas na região mediana, hialinas, oblanceoladas, superfícies glabras, margens glabras, ápice acuminado; ramos estigmáticos simples, maiores que os ramos nectaríferos. Ramos estigmáticos e nectaríferos liberando-se na coluna do gineceu na mesma altura.

Comentários: Bastante distinta de Syngonanthus gracilis, é uma espécie robusta, muitas vezes formando touceiras de indivíduos com folhas lanceoladas e capítulos creme. Cresce geralmente em áreas sombreadas. Recentemente descrita para restingas do sudeste e nordeste (Hensold et. al. 2012). Ocorre em regiões úmidas e próximas a lagoas. Até o presente momento não havia registros dessa espécie para o Espírito Santo. Material examinado selecionado: Linhares, 21.X.1994, D. Araújo 10098 (GUA); 25.X.1994, D.A. Folli 2402 (CVRD, RFA); 22.XI.2000, D. Araújo 10732 (GUA); 11.VII.2006, D.A. Folli 5318 (CVRD, RFA); 7.XI.2014, L.E.F. Silva 34 (CVRD, RFA).

9. Tonina fluviatilis Aubl., Hist. Pl. Guiane 2: 857. 1775.

Fig. $2 \mathrm{f}$

Plantas de 10,8-50,4 cm alt. Folhas dispostas ao longo do caule, $0,6-1,8 \times 0,1-0,4 \mathrm{~cm}$, lanceoladas, superfícies hirsutas à glabrescentes, margens ciliadas à glabrescentes, ápice agudo. Espatas 0,7-1,3 cm, abertas, glabras ou raramente pilosas, ápice agudo. Escapos partindo da axila das folhas, solitários, nunca formando arranjo umbeliforme, 2-4 mm compr., glabros. Capítulos castanho-claros, ca. $3 \mathrm{~mm}$ diâm., hemisféricos à esféricos. Brácteas involucrais castanho-claros, ca. $3 \mathrm{~mm}$ compr., não ultrapassando o diâmetro do capítulo, largoelípticas, superfícies pouco pilosas à glabrescentes, margens ciliadas, ápice acuminado. Brácteas florais castanhas, ca. $2 \mathrm{~mm}$ compr., obovais, superfícies pilosas à glabrescentes, margens ciliadas à glabrescentes, ápice acuminado. Flor estaminada ca. $2 \mathrm{~mm}$ compr., pedicelo ca. $0,5 \mathrm{~mm}$ compr., superfícies glabras; sépalas castanhas, unidas na base cobrindo o ápice das pétalas, livres, obovais, superfícies glabras, margens glabras, ápice acuminado; pétalas hialinas, livres, anteras dorsifixas. Flor pistilada ca. 2,5 mm compr., subsésseis; sépalas castanhas, livres, obovais, superfícies glabrescentes, margens ciliadas, ápice acuminado; pétalas reduzidas a lobos com longos tricomas ou nulas sobre antóforo carnoso, totalmente livres, estreito-elípticas à lineares, superfícies pilosas, margens ciliadas, ápice agudo; ramos estigmáticos bífidos, maiores que os ramos nectaríferos. Ramos estigmáticos e nectaríferos liberando-se na coluna do gineceu na mesma altura.

Comentários: Formam grandes populações dentro de corpos d'água. Pode ser facilmente distinta das demais espécies da reserva uma vez que seus indivíduos possuem folhas dispostas ao longo do extenso caule, espatas abertas e pétalas da flor pistilada reduzidas a pequenos lobos com longos tricomas. Distribui-se em diversos países nas Américas: Brasil, Colômbia, Equador, Guiana, Guiana Francesa, México, Peru, Suriname e Venezuela. No Brasil sua ocorrência é atribuída aos estados do Acre, Amazonas, Bahia, Ceará, Espírito Santo, Maranhão, Pará, Paraíba, Pernambuco, Piauí, Rio de Janeiro, São Paulo e Tocantins (Ruhland 1903; Sano \& Giulietti 2012; BFG 2015). É a única espécie aquática, sendo que ocorre em lagoas e bordas de lagoas. Apresenta flores e frutos principalmente nos meses de mais úmidos.

Material examinado selecionado: Linhares, 30.III.1993, D.A. Folli 1855 (CVRD, RFA); 16.XII.1997, O.J. Pereira \& A.M. Assis 5766 (VIES); 5.IV.2002, D.A. Folli 4231 (CVRD, RFA); 12.II.2007, M.O.D. Pivari 511 (CVRD); 18.IV.2011, J.C. Lopes et al. 252 (RB); 6.XI.2014, L.E.F. Silva 29 (CVRD, RFA).

\section{Agradecimentos}

$\mathrm{O}$ primeiro autor agradece à FAPERJ, a bolsa de iniciação científica concedida (E26/100.912/2013). O segundo autor agradece a Alexander von Humboldt Foundation, à UFRJ (ALV 2013), ao CNPq (proc. 470349/2013-1) e à FAPERJ (E26/112.476 - INST, E-26/110.031/2011, E-26/111.392/2012, E-26/010.001626/2014 BIOTA). Ambos agradecem também aos curadores dos herbários visitados, em especial ao Geovani Siqueira, curador do herbário CVRD.

\section{Referências}

BFG. 2015. Growing knowledge: an overview of Seed Plant diversity in Brazil. Rodriguésia 66: 1085-1113.

Garay, I.; Kindel, A.; Louzada, M.A.P. \& Santos, R.D. 2003. A Floresta Atlântica de Tabuleiros: diversidade funcional da cobertura arbórea. Vozes, Petropólis. Pp. 16-26. 
Giulietti, A.M.; Amaral, M.C.E. \& Bittrich, V. 1995. Phylogenetic analysis of inter- and infrageneric relationships of Leiothrix Ruhland (Eriocaulaceae). Kew Bulletin 50: 55-71.

Giulitti, A.M.; Andrade, M.J.G.; Scatena, V.L.; Trovó, M.; Coan, A.I.; Sano, P.T.; Santos, F.A.R.; Borges, R.L.B. \& Van Den Berg, C. 2012. Molecular phylogeny, morphology and their implications for the taxonomy of Eriocaulaceae. Rodriguésia, 63: 1-19.

Giuliettti, A.M. \& Hensold, N. 1987. Eriocaulaceae. In: Giulietti, A.M.; Menezes, N.L.; Pirani, J.R.; Meguro, M. \& Wanderley, M.G.L. Flora da Serra do Cipó, Minas Gerais: caracterização e lista das espécies. Boletim de Botânica da Universidade de São Paulo 9: 112-116.

Giulietti,A.M. \& Hensold, N. 1990. Padrões de distribuição geográfica dos gêneros de Eriocaulaceae. Acta Botanica Brasilica 4: 133-159.

Giulietti, A.M.; Menezes, N.L.; Piani, J.R.; Meguro, M. \& Wanderley, M.G.L. 1987. Flora da Serra do Cipó, Minas Gerais: caracterização e lista das espécies. Boletim de Botânica da Universidade de São Paulo 9: 1-151.

Giulietti, A.M. \& Parra, L.R. 1995. Eriocaulaceae. In: Stannard, B.L. Flora of the Pico das Almas, Chapada Diamantina, Bahia, Brasil. The Royal Botanical Gardens, Kew, London. Pp. 684-704.

Giulietti, A.M.; Parra, L.R. \& Sano, P.T. 2003. Eriocaulaceae. In: Zappi, D.C.; Lucas, E.; Stannard, B.L.; Lughadha, E.N.; Pirani, J.R.; Queiroz, L.P.; Atkins, S.; Hind, D.J.N.; Giulietti, A.M.; Harley R.M. \& Carvalho A.M. Lista das plantas vasculares de Catolés, Chapada Diamantina, Bahia, Brasil. Boletim de Botânica da Universidade de São Paulo 21: 393-395.

Giulietti, A.M.; Scatena, V.L.; Sano, P.T.; Parra, L.R.; Queiroz, L.P.; Harley, R.M.; Menezes, N.L.; BenkoYseppon, A.M.; Salatino, A.; Salatino, M.L.; Vilegas, W.; Santos, L.C.; Ricci, C.V.; Bonfim, M.C.P. \& Miranda, E.B. 2000. Multidiciplinary studies on Neotropical Eriocaulaceae. In: Wilson, K.L. \& Morrison, D.A. (eds.). Monocots II: systematics and evolution, Melbourne. Pp. 580-589.

Harley, R.M. \& Simmons, N.A. 1986. Flórula de Mucugê: Chapada Diamantina-Bahia, Brazil. The Royal Botanical Gardens, Kew. Pp. 61-70.

Hensold, N. 1998. Flora da Serra do Cipó, Minas Gerais: Paepalanthus subg. Xeractis (Eriocaulaceae). Boletim de Botânica da Universidade de São Paulo 17: 207-218.

Hensold, N.; Oliveira, A.L.R. \& Giulietti, A.M. 2012. Syngonanthus restingensis (Eriocaulaceae): a remarkable new species endemic to Brazilian costal shrublands. Phytotaxa 40: 1-11.
Miranda, E.B. \& Giulietti, A.M. 2001. Eriocaulaceae no Morro do Pai Inácio (Palmeiras) e Serra da Chapadinha (Lençóis), Chapada Diamantina, Bahia, Brasil. Sitientibus Série Ciências Biológicas 1: 15-32.

Parra, L.R. 1998. Flora da Serra do Cipó, Minas Gerais: Syngonanthus Ruhland (Eriocaulaceae). Boletim de Botânica da Universidade de São Paulo 17: 219-254.

Parra, L.R.; Giulietti A.M.; Andrade, M.J.G. \& van den Berg, C. 2010. Reestablishment and new circumscription of Comanthera (Eriocaulaceae). Taxon 59: 1135-1146.

Peixoto, A.L. 1982. Considerações preliminares sobre a flora e a vegetação da Reserva Florestal da Companhia Vale do Rio Doce, Linhares, E.S. Cadernos de Pesquisa. Universidade Federal do Piauí. Série Botânica 1: 41-48.

Radford, A.E. 1974. Vascular plant systematics. Harper \& Row, New York. 891p.

Rizzini, C.T. 1997. Tratado de fitogeografia do Brasil: aspectos ecológicos, sociológicos e florísticos. $2^{\mathrm{a}}$ ed. Âmbito Cultural Edições Ltda., Rio de Janeiro. 747p.

Ruhland, W. 1903. Eriocaulaceae. In: Engler, A. Das Pflanzenreich. Vol. 4. Wilhelm Engelmann, Leipzig. Pp. 1-294.

Sano, P.T. 1998. Flora da Serra do Cipó, Minas Gerais: Paepalanthus sect. Actinocephalus - Eriocaulaceae. Boletim de Botânica da Universidade de São Paulo 17: 187-205.

Sano, P.T. \& Giulietti, A.M. 2012. Eriocaulaceae. In: Wanderley, M.G.L.; Shepherd, G.J.; Melhem, T.S.; Guilietti, A.M. \& Martins, S.E. (eds.). Flora fanerogâmica do estado de São Paulo. Instituto de Botânica, São Paulo. Vol. 7, pp. 173-200.

Sano, P.T.; Giulietti, A.M.; Trovó, M.; Parra, L.R. \& Muller, G. 2010. Flora de Grão-Mogol, Minas Gerais: Eriocaulaceae. Boletim de Botânica da Universidade de São Paulo 28: 125-140.

Silva, L.E.F. \& Trovó, M. 2014. A família Eriocaulaceae nas restingas do Rio de Janeiro, Brasil. Rodriguésia 65: 871-883.

Stützel, T. 1998. Eriocaulaceae. In: Kubitzki, K. The families and genera of vascular plants IV - flowering plants: Monocotyledons - Alismatanae and Comelinanae (except Graminae). Springer - Verlag, Berlin. Pp. 197-207.

Trovó, M.; Sano, P.T.; Costa, F.N. \& Giulietti, A.M. 2007. Flora fanerogâmica do Parque Nacional do Caparaó: Eriocaulaceae. Pabstia 17: 2-8

Veloso, H.P.; Rangel Filho, A.L.R. \& Lima, J.C.A. 1991. Classificação da vegetação brasileira a um sistema universal. IBGE, Departamento de Recursos Naturais e Estudos Ambientais, Rio de Janeiro. 123p.

Weberling, F. 1989. Morphology of flowers and inflorescenses. Cambridge University Press, Cambridge. 405p. 


\section{Lista de Exsicatas}

Araujo 10098 - GUA (8); 10732 - GUA (8). Araujo \& Domingos 8101 - GUA (7). Araujo \& Oliveira 7979 - GUA (1). Assis 2231 - MBML (2); 2241 - MBML (1). Biral 957 - CVRD (7). Braga et al. 7304 - CVRD, RB, RFA (1). Costa 335 - RB (3); 336 - RB (3). Farias 98 - CVRD, RFA (1); 567 - CVRD (1); 568 - CVRD (3); 569 - CVRD (6); 587 - CVRD (4). Farney et al. 280 - RB (6). Ferreira 27 - CVRD (1); 57 - VIES (5); 58 - VIES (1); 88 - VIES (1); 90 - VIES (5); 98 - CVRD, VIES (3); 109 - VIES (1); 110 - CVRD, VIES (3); 136 - VIES (3); 154 - CVRD, VIES (4); 155 - CVRD (7). Flores 942 - CVRD (1). Flores \& Romão 1240 - CVRD (3). Folli 725 - CVRD, RFA (5); 736 - CVRD, RFA (1); 737 - CVRD, RFA (1); 738 - CVRD, RFA (1); 749 - CVRD, RFA (6); 1583 - CVRD (1); 1592 - CVRD, RFA (7); 1731 - CVRD (4); 1826 - CVRD, RFA (6); 1855 - CVRD, RFA (9); 1873 - CVRD (3); 2402 - CVRD, RFA (8); 2937 - CVRD, RFA (4); 3465 - CVRD, RFA (5); 3892 - CVRD, RFA (3); 4231 - CVRD, RFA (9); 4793 - CVRD (7); 4794 - CVRD, RFA (6); 5085 - CVRD, RFA (1); 5289 - CVRD, RFA (3); 5318 - CVRD, RFA (8); 5580 - CVRD, RFA (6). Fraga 583 - MBML (1); 584 - MBML (6). Freire 103 - CVRD (6). Lima H.C. 1673 - RB (1). Lima H.C. et al. 1910 - RB (4). Lima J.C.A. 04 - RB (7).Lombardi et al. 9654 - CVRD, RFA (1). Lopes et al. 252 - RB (9); 256 - RB (1). Lucas E. 889 - CVRD (1). Maas et al. 9869 - CVRD, RFA (1). Martinelli et al. 4081 - CVRD (6); 12232 - RB (5). Mello-Silva 1550 - CVRD (1). Morokawa 402 - RB (4). Pereira 1069 - VIES (1). Pereira \& Assis 5766 - VIES (9). Pereira et al. 6313 - VIES (5); 6323 - VIES (4). Pivari 511 - CVRD (9). Romão 1233 - CVRD (4). Rando 172 - CVRD (1); 173 - RB (1). Rando et al. 164 - CVRD, RB (3); 168 - RB (7). Silva B.R. \& Nardruz 1393 - RB (6). Silva L.E.F. 26 - CVRD, RFA (7); 27 - CVRD, RFA (3); 28 - CVRD, RFA (4); 29 - CVRD, RFA (9); 30 - CVRD, RFA (6); 31 - CVRD, RFA (1); 32 - CVRD, RFA (5); 34 - CVRD, RFA (8); 35 - CVRD, RFA (2); 36 - CVRD, RFA (5); 37 - CVRD, RFA (1); 38 - CVRD, RFA (3); 39 - CVRD, RFA (4); 40 - CVRD, RFA (6); 41 - CVRD, RFA (7). Siqueira 224 - CVRD, RFA (7). Sobral 3987 - CVRD (3); 4002 - CVRD (1); 4097 - CVRD (7); 4692 - CVRD (2). Stehmann 4658 - CVRD (7); 4768 - CVRD (4). Stehmann et al. 4660 - CVRD, RFA (3); 4667 - CVRD, RFA (6); 4693 - CVRD, RFA (1); 4769 - CVRD, RFA (6). Sucre 8315 - RB (4); 8385 - RB (1); 8390 - RB (5); 8399 - RB (2); 8413 - RB (6). Trovó 253 - CVRD, RFA (3); 254 - CVRD, RFA (7); 255 - CVRD (1); 256 - CVRD, RFA (4); 257 - CVRD, RFA (5). 